\title{
An Exercise Rehabilitative Solution to Work-Related Musculoskeletal Lower Back Pain among Nurses
}

\author{
Yvonne Paul1, Terry J. Ellapen², Mariette Swanepoel2, Henriette V. Hammill², Marco Barnard2, \\ Bongani T. Qumbu²
}

${ }^{1}$ Department of Sport and Dental Therapy, Faculty of Health Science, Tshwane University of Technology, Pretoria, South Africa ${ }^{2}$ Faculty of Health Sciences, PhASRec, North-West University, Potchefstroom, South Africa

Email: tellapen1@yahoo.com

How to cite this paper: Paul, Y., Ellapen, T.J., Swanepoel, M., Hammill, H.V., Barnard, M. and Qumbu, B.T. (2018) An Exercise Rehabilitative Solution to Work-Related Musculoskeletal Lower Back Pain among Nurses. Open Journal of Orthopedics, 8, 322-330.

https://doi.org/10.4236/ojo.2018.88035

Received: March 22, 2018

Accepted: August 14, 2018

Published: August 17, 2018

Copyright (C) 2018 by authors and Scientific Research Publishing Inc. This work is licensed under the Creative Commons Attribution International License (CC BY 4.0).

http://creativecommons.org/licenses/by/4.0/

\begin{abstract}
The attrition of professional nurses is a sad reality. Work-related musculoskeletal lower back pain (WRMLBP) among nurses has been cited as a factor of increased sick leave and poor health. Occupational predisposing factors of lower back pain are strenuous physical stresses of nursing, obesity and poor physical conditioning. Regular stretching and strengthening exercises dissipate lower back pain. This commentary's objectives are to explain the association between obesity and lower back pain and the exercise mechanism that dissipates this pain, thereby concluding that nurses should consider regular exercise as a therapeutic option.
\end{abstract}

\section{Keywords}

Nurses, Lower Back Pain, Exercise

\section{Introduction}

The attrition of professional nurses is a sad reality, estimated to be ranging at $24 \%$ biennially [1]. Literature has indicated that the leading factors of premature termination of service are poor salaries, long arduous working hours, inadequate in-house training, minimal workplace incentives and rewards, clinical infra-structure and equipment related challenges and personal problems (career dissatisfaction, disgruntled relationships with colleagues and other medical professionals and illness and poor health) [2] [3] [4]. Many of the aforementioned predisposing factors influencing the attrition of nurses are extrinsic in nature, being regarded as hospital management related challenges. This commentary 
focuses on work-related illness and poor health, more specifically WRMLBP.

WRMLBP is responsible for the increased number of annual sick days and poor health, which contributes to premature retirement of nursing staff [5] [6]. The lower back has been identified as the most susceptible anatomical site of musculoskeletal pain, followed by the shoulders and neck respectively [5] [6]. WRMLBP has high occurrence ranging between 58\% and 79\% among nursing personnel [6] [7] [8]. Occupational predisposing risk factors cited were awkward habitual working positions unremitting for prolonged periods during patient transfer, strenuous physical stresses of the nursing profession, their poor health and fitness conditioning status as well as obesity [4] [6] [7] [9] (Figure 1).

There has been numerous systematic reviews published concerning WRMLBP among nurses [4] [8] [10] [11] [12]. Yassi and Lockhart and Schlossmacher and Amaral identified a casual association between nursing tasks and WRMLBP [9] [10]. Ellapen and Narsigan's systematic review described the kinesiology of prolonged vertebral flexion adopted by nurses during patient transfer activities that precipitates lower back pain [12]. Smedley et al. identified the gynoid somatotype (obesity) as a primary intrinsic predisposing risk factor of lower back pain among nurses [13].

Several empirical investigations examined the efficacy of the different intervention strategies to curb WMSP among nurses [14]. Smedley et al. and Warming

\section{EXTRINSIC FACTORS (Hospital management related challenges)}

(i) Poor salaries

(ii) Long arduous working hours

(iii) Inadequate in-house training

(iv) Minimal workplace incentives and inadequate rewards

(v) Clinical infra-structure and equipment challenges

\section{INTRINSIC FACTORS (Personal problems)}

(i) Career dissatisfaction

(ii) Disgruntled relationships with colleagues and other medical professionals

(iii) Illness and poor health

$>$ Poor fitness status (cardiorespiratory function)

$>$ Poor muscle strength and endurance

$>$ Poor flexibility

$>$ Overweight and obesity

$>$ Work-related musculoskeletal pain and injury

Factors influencing work-related musculoskeletal pain

turning, bathing, dressing, seating patients in the bed and/or chairand transferring patients

> helping patients, while position yourself in awkward positions for prolonged periods

Figure 1. Factors influencing premature termination of professional nursing careers. 
et al. reported that teaching nurses the proper lifting technique during patient transfer reduces lower back pain [13] [15]. Proper et al. and Yuan et al. demonstrated that regular adherence to exercise and physical activity curbs the lower back pain among nurses [16] [17]. Regular flexibility exercises stretch the tight para-spinal muscles of the lower back which, elongates muscle contractures, whilst facilitating the decompression of intervertebral discs and dissipating muscle spasms [18]. Specific strengthening exercise will shorten laxed muscles and increase their strength and endurance when these muscles act as agonists, synergists, fixators and neutralizers to prevent unwanted muscle movement producing lower back pain when performing strenuous physical tasks [18]. Exercise therapists have being prescribing strengthening and stretching exercises to effectively dissipate lower back [18] [19].

Nelson et al. reported that the primary limitation that prevents nurses from adhering to physical activity programmes is their busy work schedules [5]. This paper briefly reviews the kinesiological association of obesity and WRMLBP. Thereafter an exercise therapeutic intervention has been prescribed to assist in resolving the pain. The authors' intention is to gently encourage nurses to engage in regular physical activity to curb the incidence of lower back pain.

\subsection{Aetiology of Lower Back Pain in Association to Obesity}

The association of WRMLBP and obesity entails the comprehension of both global and local musculature's abnormal force couple relationships. A hallmark characteristic of female obesity is the gynoid somatotype; increased accumulation of body fat around the waist and hip [13]. Obese nurses have an anteriorly tilted pelvis (short arc pelvis on femur hip flexion) and lumbar lordosis that produces lower back pain (Figure 2) [20]. The anterior rotation of the pelvis is instigated by the habitual concentric contraction of the strong hip flexors (iliopsoas, rectus femoris), which eccentrically lengthen the hip extensors (gluteus medius, minimus and maximus) producing an abnormal force couple relationship (Figure 2) [19] [21]. Habitual eccentric loading of the hip extensors leads to muscle strains that precipitate lower back pain [17].

Concentric strengthening of hip extensors is needed, to reverse the anterior tilt to a neutral aligned pelvis. Mansfield and Neumann recommended closed kinetic chain exercise (CKCE), strengthening of the gluteal muscles, which counternutates the sacrum and subsequently posteriorly rotates the anteriorly tilted pelvis to a neutral pelvis, by drawing the muscle's origin to its insertion [19]. Habitual concentric contraction of hip flexors produces hip flexor contractures and shortening of the iliofemoral and pubiofemoral ligaments, which needs to be statically stretched to regain a neutral aligned pelvis [18]. Figure 2 shows the alteration in pelvic alignment that produces weak elongated abdominal and gluteal muscles in contrast to the shortened para-spinal and flexor muscles associated with obesity. This biomechanical mechanism explains the association between obesity and lower back pain. 


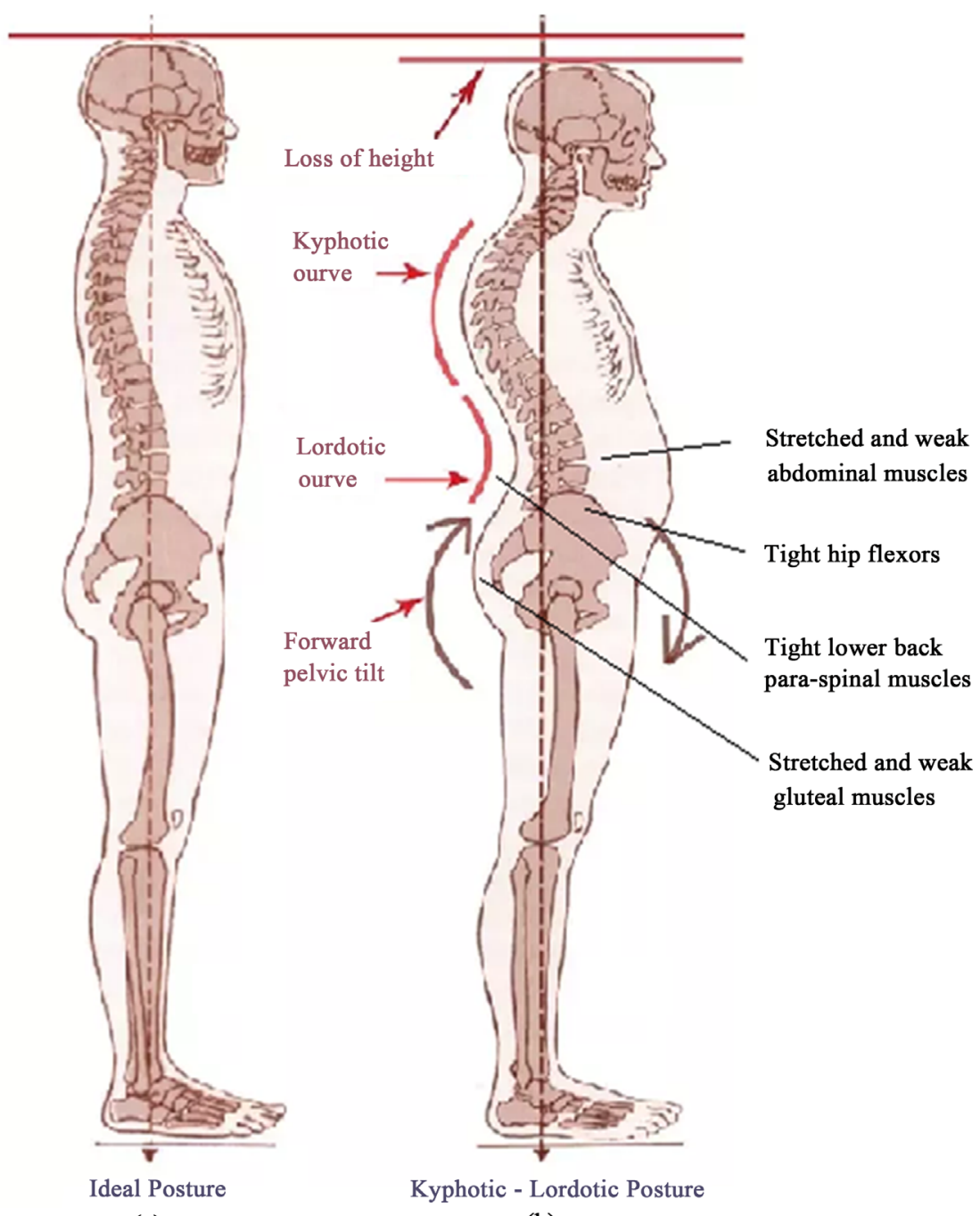

(a)

(b)

Figure 2. Association between obesity and lumbopelvic orientation [21].

\subsection{Intervertebral Segment Instability due to Abnormal Force-Couple Relationship of the Local Intervertebral Muscles}

The global hip flexor/extensor abnormal force-couple relationship of the lumbopelvis precipitates further intervertebral segment misalignment [18] [19]. The anteriorly tilted pelvis pulls the sacral promontory forward away from the lumbar vertebrae increasing the sacro-horizontal angle at the lumbosacral junction and producing lordosis [19]. Lumbar lordosis eccentrically lengthens the transverse abdominis (TA) and anterior longitudinal ligament whilst concentrically shortening the multifidus, rotators, interspinalis, intertransversarus, ligmentumflavum, posterior longitudinal and interspinous ligaments. Abdominal obesity further exacerbates the aforementioned pathomechanics [21]. This creates a local abnormal force-couple relationship between the sacral promontory and the lumbar vertebra muscles. Mansfield and Neumann reported that the altered lumbosacral junction may perpetuate into anterior spondylolisthesis [19]. In an 
attempt to maintain an erect posture the person adopts a kypolordotic posture that hyperextends the lumbar vertebrae, producing abnormal local force-couple relationships between each successive lumbar vertebral segment [19] [21]. Chronic alteration of the sacro-horizontal angle and lumbar lordosis produce transversospinal muscle contracture. Therefore, intervertebral segmental stabilization is required to strengthen the TA and eccentrically lengthen the posterior transversospinal muscle contractures.

\subsection{How Does the Strenuous Physical Tasks of Nursing Causes Lower Back Pain?}

Nurses comply with various strenuous physical tasks that require them to position their bodies in awkward positions for prolonged situations. These nurse-patient interaction tasks include turning, bathing, dressing, seating patients in the bed and/or chair and transferring patients [6] [7] [14] [22]. Transferring albeit overweight and obese patients may be from the bed onto a wheelchair or stationary chair, or stretcher or onto the toilet [14]. In addition the nurses are also responsible for the reverse transfers as well.

Unfortunately these above-mentioned strenuous tasks do contribute to the WRMLBP among nurses [6] [7] [22]. All the above tasks require nurses to adopt abnormal positions that must be held statically or move very slowly [6] [7]. When nurses are transferring patients they would have flexed their hips (long arc pelvis on femur hip flexion) and hold this position for an indefinite time, eliciting concentric and eccentric contractions of the anterior and posterior lumbopelvic muscles respectively [19]. The anterior lumbopelvic muscles are initially concentrically contracted and then maintained in this shortened state for an indefinite time. Meanwhile the posterior lunbopelvic muscles are eccentrically lengthened and maintained in this state for a prolonged period. This abnormal hip flexion position exasperates the condition of nurses whose hip flexor contractures are precipitating further WRMLBP. Further, the para-spinal muscles are eccentrically lengthened for an indefinite period of time as patients are slowly lowered from bed to chair, which increases the risk of further muscle strains escalating the lower back pain [19]. Exercise therapy has successfully resolved lower back pain relating to the aforementioned predisposing mechanism of injury through the prescription of specific stretching and strengthening exercises [18].

\section{Recommendations}

Nurses should attempt to adopt better ergonomic practises during patient transfers and regularly perform core stabilization exercises [6]. Core stabilization exercises have been successful in decreasing lower back pain by increasing muscle strength and endurance [18]. The ergonomic practices include:

- Adjust patient's bed height to the nurse's relative hip (ASIS height), so that the nurse does not need to hyperextend her back when she is transferring the patient onto a bed height higher than her hip. 
- Nurses must bend their knees when lifting patients to protect their lower back from injury.

- When lifting patients, nurses should attempt to hold the patients close to their bodies to reduce the stress on their lower back.

- Nurses are encouraged to resume an erect standing posture after continuous prolonged lumbopelvic flexion and/or patient transfers.

- Nurses must refrain from wearing high heel shoes when consulting, as it increases their anterior pelvic tilt.

Core stabilization includes strengthening and stretching exercises. Nurses should seek medical consent from a medical practitioner, exercise therapists (biokineticist and physiotherapist) before engaging in these recommended exercises. The stabilization exercises should include the following;

- All stretching should be performed statically for a minimum of 30 seconds per stretch, twice.

- Muscles that need to be stretched include the iliopsoas, rectus femoris, sartorius, lumbar erector spinae and quadratus lumborum.

- Muscles that need to be strengthened include the gluteus minimus, medius and maximus, hamstrings group and abdominal group (rectus abdominis, external and internal obliques and transverse abdominis).

- Nurses must be encouraged to walk briskly for 20 minutes daily to decrease obesity.

Patients complying with the exercise guidelines will experience a compressive sensation around their lower back (biomechanically known as force closure of the lumbopelvic hip complex), observe better posture (reduction in lordotic curve) and decrease pain sensation leading to no pain. It is important to note that subsequent exercise prescription can serve for prevention and rehabilitation of lower back pain [18] [19]. Physiotherapists and biokineticists are functional exercise therapists who will be invaluable therapeutic practitioners, who may prescribe individualized exercise rehabilitative regimes, demonstrate these exercises and monitor patient progress [12].

Core stabilization programme

See Table 1 and Table 2.

Table 1. Stretching exercises (adapted from Ellapen et al.) [23].

\begin{tabular}{|c|c|c|c|c|c|}
\hline \multicolumn{6}{|c|}{ Stretching Programme } \\
\hline $\begin{array}{l}\text { Muscle group } \\
\text { been stretched }\end{array}$ & Exercise & Duration & Repetitions & Goal & Picture \\
\hline $\begin{array}{c}\text { Quadratus } \\
\text { lumborum, lower } \\
\text { back muscles }\end{array}$ & $\begin{array}{l}\text { Seated } \\
\text { hip } \\
\text { flexion }\end{array}$ & 30 seconds & 2 & $\begin{array}{c}{ }^{*} \text { Increased lower } \\
\text { back flexibility } \\
\text { *Able to bend back } \\
\text { without pain }\end{array}$ & \\
\hline $\begin{array}{l}\text { Rectus femoris, } \\
\text { iliopsoas and } \\
\text { satorius }\end{array}$ & Lunge & 30 seconds & 2 & $\begin{array}{c}{ }^{*} \text { Increased front } \\
\text { thigh and } \\
\text { hip flexibility }\end{array}$ & \\
\hline
\end{tabular}


Table 2. Strengthening exercises (adapted from Ellapen et al.) [23].

\begin{tabular}{|c|c|c|c|c|c|}
\hline \multicolumn{6}{|c|}{ Strengthening Programme } \\
\hline $\begin{array}{l}\text { group been } \\
\text { strengthened }\end{array}$ & Exercise & Sets & Repetitions & Goal & Picture \\
\hline $\begin{array}{l}\text { Multifudus } \\
\text { and transverse } \\
\text { abdominis } \\
\text { activation }\end{array}$ & $\begin{array}{l}\text { Controlled, gentle } \\
\text { drawing in your lower } \\
\text { abdominal wall } \\
\text { towards your spine. } \\
\text { Hold contraction for } \\
10 \text { seconds and relax. } \\
\text { Maintain this muscle } \\
\text { activation for all } \\
\text { core exercises. }\end{array}$ & 2 & 10 & $\begin{array}{l}\text { Increased } \\
\text { compressive } \\
\text { force around } \\
\text { the waist }\end{array}$ & \\
\hline $\begin{array}{c}\text { Rectus } \\
\text { abdominis }\end{array}$ & $\begin{array}{l}\text { Supine, with } \\
\text { knees bent and } \\
\text { perform crunches. }\end{array}$ & 2 & 10 & $\begin{array}{l}\text { Increased } \\
\text { compressive } \\
\text { force around } \\
\text { the waist }\end{array}$ & \\
\hline $\begin{array}{l}\text { Gluteus and } \\
\text { hamstrings }\end{array}$ & $\begin{array}{c}\text { Hold pelvis in neutral } \\
\text { position by activating } \\
\text { multifudus and } \\
\text { TA then extend the hip. }\end{array}$ & 2 & 10 & $\begin{array}{l}\text { Increased } \\
\text { compressive } \\
\text { force around } \\
\text { the waist }\end{array}$ & \\
\hline $\begin{array}{l}\text { Gluteus and } \\
\text { hamstrings }\end{array}$ & CKCE: wall squats & 2 & 10 & $\begin{array}{l}\text { Stronger } \\
\text { gluteus and } \\
\text { hamstrings } \\
\text { strength and } \\
\text { endurance }\end{array}$ & \\
\hline $\begin{array}{l}\text { Gluteus and } \\
\text { hamstrings }\end{array}$ & $\begin{array}{l}\text { Hold pelvis in neutral } \\
\text { position by activate } \\
\text { multifudus and TA. } \\
\text { Then extend opposite } \\
\text { arm and leg. }\end{array}$ & 2 & 10 & $\begin{array}{l}\text { Stronger } \\
\text { gluteus and } \\
\text { hamstrings } \\
\text { strength and } \\
\text { endurance }\end{array}$ & \\
\hline
\end{tabular}

\section{Conclusion}

There is an association between obesity and lower back pain that can be resolved through core stabilization exercises. Therefore, it is recommended that nurses experiencing lower back pain should consider the option of therapeutic exercise.

\section{Conflicts of Interest}

The authors declare no conflicts of interest regarding the publication of this paper.

\section{References}

[1] Okechukwu, C.A., Bacic, J., Velasquez, E. and Hammer, L.B. (2016) Marginal Structural Modelling of Associations of Occupational Injuries with Voluntary and Involuntary Job Loss among Nursing Home Workers. Occupational Environmental Medicine, 73, 175-182. https://doi.org/10.1136/oemed-2015-103067

[2] Roos, E., Fichardt, A.E., Mackenize, M.J. and Raubenheimer, J. (2016) Attrition of 
Undergraduate Nursing Students at Selected South African Universities. Curationis, 39, a1558. https://doi.org/10.4102/curationis.v39i1.1558

[3] Twibbel, R. and Pierce, J. (2012) Tripping over the Welcome Mat: Why New Nurses Don't Stay and What the Evidence Say We Can Do about It. American Nursing Today, 7, 6.

[4] Long, M.H., Johnston, V. and Bogossian, F. (2012) Work-Related Upper Quadrant Musculoskeletal Disorders in Midwives, Nurses and Physicians: A Systematic Review of Risk Factors and Functional Consequences. Applied Journal of Ergonomics, 43, 455-467. https://doi.org/10.1016/j.apergo.2011.07.002

[5] Nelson, A., Harwood, K.J., Tracey, C.A. and Dunn, K.L. (2008) Myths and Facts about Safe Patient Handling in Rehabilitation. Rehabilitative Nursing, 33, 10-17. https://doi.org/10.1002/j.2048-7940.2008.tb00187.x

[6] Dos Santos, E.C., Andrade, R.D., Lopes, S.G.R. and Valgas, C. (2017) Prevalence of Musculoskeletal Pain in Nursing Professionals Working in Orthopedic Setting. Revista Dor, 18, 298-306. https://doi.org/10.5935/1806-0013.20170119

[7] Munabi, I.G., Buwembo, W., Kitara, D.L., Ochieng, J. and Mwaka, E.S. (2014) Musculoskeletal Disorder Risk Factors among Nursing Professionals in Low Resource Settings: A Cross-Sectional Study in Uganda. BMC Nursing, 13, 7. https://doi.org/10.1186/1472-6955-13-7

[8] Aizpour, Y., Delipishen, A., Montazeri, Z. and Sayehmiri, K. (2017) Prevalence of Low Back Pain in Iranian Nurses: A Systematic Review and Meta-Analysis. BMC Nursing, 16, 50. https://doi.org/10.1186/s12912-017-0243-1

[9] Yassi, A. and Lockhart, K. (2013) Work-Relatedness of Low Back Pain in Nursing Personnel: A Systematic Review. International Journal of Occupational Environmental Health, 19, 223-244. https://doi.org/10.1179/2049396713Y.0000000027

[10] Long, M.H., Bogossian, F.E. and Johnston, V. (2013) The Prevalence of Work Related Neck, Shoulder, and Upper Back Musculoskeletal Disorders among Midwives, Nurses, and Physicians: A Systematic Review. Workplace Health Safe, 61, 223-229.

[11] Schlossmacher, R. and Amaral, F.G. (2012) Low Back Injuries Related to Nursing Professionals Working Conditions: A Systematic Review. Work 41 Supplements, 1, 5737-5738.

[12] Ellapen, T.J. and Narsigan, S. (2014) Work Related Musculoskeletal Disorders among Nurses: Systematic Review. Journal of Ergonomics, S4, 003.

[13] Smedley, J., Trevelyan, F., Inskip, H., Buckle, P. and Cooper C. (2003) Impact of Ergonomic Intervention on Back Pain among Nurses. Scandinavian Journal of Work Environmental Health, 29, 117-123. https://doi.org/10.5271/sjweh.713

[14] Choi, S.D. and Brings, K. (2016) Work-Related Musculoskeletal Risks Associated with Nurses and Nursing Assistants Handling Overweight and Obese Patients: A Literature Review. Work, 53, 439-448. https://doi.org/10.3233/WOR-152222

[15] Warming, S., Ebbehøj, N.E., Wiese, N., Larsen, L.H. and Duckert, J. (2008) Little Effect of Transfer Technique Instruction and Physical Fitness Training in Reducing Low Back Pain among Nurses: A Cluster Randomised Intervention Study. Ergonomics, 51, 1530-1548. https://doi.org/10.1080/00140130802238606

[16] Proper, K.I., Koning, M., van derBeek, A.J., Hildebrandt, V.H. and Bosscher, R.J. (2003) The Effectiveness of Worksite Physical Activity Programs on Physical Activity, Physical Fitness, and Health. Clinical Journal of Sports Medicine, 13, 106-117. https://doi.org/10.1097/00042752-200303000-00008

[17] Yuan, S.C., Chou, M.C., Hwu, L.J., Chang, Y.O. and Hsu, W.H. (2009) An Interven- 
tion Program to Promote Health Related Physical Fitness in Nurses. Journal of Clinical Nursing, 18, 1404-1411. https://doi.org/10.1111/j.1365-2702.2008.02699.x

[18] Prentice, W.E. (2011) Rehabilitation Techniques for Sports Medicine and Athletic Training. Human Kinetics, Champaign.

[19] Mansfield, P.J. and Neumann, D.A. (2009) Essentials of Kinesiology for the Physical Therapist Assistant. MOSBY Elsevier, St Louis.

[20] Shirr, R., Karppinen, J., Leino-Arjas, P., Solovieva, S. and Viikari-Juntura, E. (2010) The Association between Obesity and Low Back Pain: A Meta-Analysis. American Journal of Epidemiology, 171, 135-154. https://doi.org/10.1093/aje/kwp356

[21] Kendall, H.O. (2005) Muscles, Testing and Function. Lippincott Williams \& Wilkins, Philadelphia.

[22] Anap, D.B., Iyer, C. and Rao, K. (2013) Work Related Musculoskeletal Disorders among Hospital Nurses in Rural Mahasahtra, India. International Journal of Research in Medical Sciences, 1, 101-107. https://doi.org/10.5455/2320-6012.ijrms20130513

[23] Ellapen, T.J., Van Heerden, H.J. and Paul, Y. (2015) Practical Advice Pertaining to Lower Back Pain among Dentists. Journal of Dental Application, 2, 188-189. 